\title{
Comparison of del Nido and histidine-tryptophan-ketoglutarate cardioplegia solutions in pediatric patients undergoing open heart surgery: A prospective randomized clinical trial
}

\author{
Sachin Talwar, MCh, ${ }^{a}$ Sujoy Chatterjee, $\mathrm{MCh},{ }^{\mathrm{a}}$ Vishnubhatla Sreenivas, $\mathrm{PhD},{ }^{\mathrm{b}}$ Neeti Makhija, MD, \\ Poonam Malhotra Kapoor, MD, ${ }^{\mathrm{c}}$ Shiv Kumar Choudhary, $\mathrm{MCh},{ }^{\mathrm{a}}$ and Balram Airan, $\mathrm{MCh}^{\mathrm{a}}$
}

\section{ABSTRACT}

Objectives: We conducted a prospective randomized controlled trial to compare del Nido (DN) and histidine-tryptophan-ketoglutarate (HTK) cardioplegia solution in pediatric patients undergoing intracardiac tetralogy of Fallot repair.

Methods: One hundred consecutive patients 12 years of age or younger, undergoing intracardiac repair of tetralogy of Fallot were randomized into DN $(n=50)$ and HTK $(\mathrm{n}=50)$ groups. Cardioplegia strategy consisted of a single dose of DN $(20 \mathrm{~mL} / \mathrm{kg})$ or HTK $(6 \mathrm{~mL} / \mathrm{kg} / \mathrm{min}$ for 6 minutes $)$. Primary outcome was cardiac index (CI). Secondary outcomes were ventricular arrhythmias post crossclamp release, time to peripheral rewarming, duration of mechanical ventilation, inotropic score, intensive care unit and hospital stay, and serum levels of troponinI, interleukin-6, and tumor necrosis factor- $\alpha$. Ultrastructural changes in the myocardium were assessed.

Results: CI was significantly higher in the DN group compared with the HTK group at $6(P=.005)$ and 24 hours $(P<.001)$ after surgery. It was on an average $0.44 \mathrm{~L} / \mathrm{min} / \mathrm{m}^{2}$ higher in the DN group at any time point $(P=.004)$. Time for complete cessation of electrical activity was longer in the HTK group $(P=.01)$ and more patients in the HTK group had ventricular arrhythmias post cross-clamp release $(P=.03)$. Duration of mechanical ventilation $(P=.006)$, intensive care unit stay $(P=.05)$, and hospital stay $(P<.001)$ were lower in the DN group. Patients in the DN group had lower troponin I levels 24 hours after cardiopulmonary bypass $(P<.001)$. Electron microscopic studies showed more myocardial edema $(P=.02)$ and myofibrillar disarray $(P=.04)$ in the HTK group along with lower glycogen stores $(P=.04)$. DN cardioplegia was more cost-effective than HTK cardioplegia $(P<.001)$.

Conclusions: DN cardioplegia was associated with better preservation of CI, less duration of mechanical ventilation, shorter intensive care unit and hospital stays, lower inotropic scores, and less release of troponin-I. Electron microscopy showed less myocardial edema and better preservation of the myofibrillar architecture and glycogen stores in the DN group. (J Thorac Cardiovasc Surg 2019;157:1182-92)

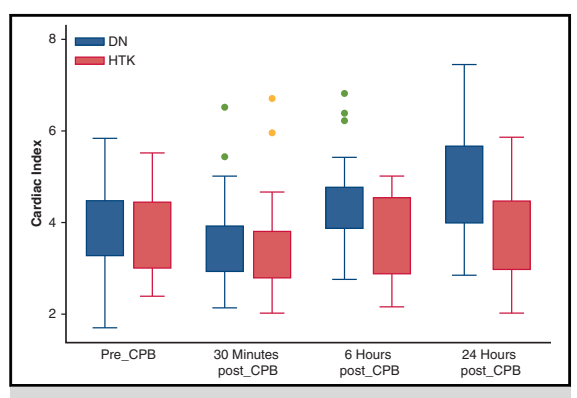

Comparison of cardiac indices $\left(\mathrm{L} / \mathrm{min} / \mathrm{m}^{2}\right)$ between the DN and HTK group.

\section{Central Message}

$\mathrm{DN}$ cardioplegia was associated with better $\mathrm{CI}$, less need of mechanical ventilation, ICU, and hospital stay, lower inotropic scores, and less release of Trop-I. Electron microscopic findings favored DN.

\section{Perspective}

One hundred patients who underwent TOF repair received either DN or HTK cardioplegia. $\mathrm{DN}$ cardioplegia was associated with better preservation of CI, less duration of mechanical ventilation, ICU, and hospital stay, lower inotropic scores, and less release of Trop-I. Electron microscopy revealed less myocardial edema and better preservation of the myofibrillar architecture and glycogen stores in the DN group.

See Commentary on page 1193.
From the Departments of acCardiothoracic and Vascular Surgery, ${ }^{b}$ Biostatistics, and ${ }^{\mathrm{c}}$ Cardiac Anesthesiology, All India Institute of Medical Sciences, New Delhi, India

Read at the 98th Annual Meeting of The American Association for Thoracic Surgery, San Diego, California, April 28-May 1, 2018.

Received for publication April 23, 2018; revisions received Sept 25, 2018; accepted for publication Sept 27, 2018

Address for reprints: Sachin Talwar, MCh, Department of Cardiothoracic and Vascular Surgery, All India Institute of Medical Sciences, New Delhi 110029, India (E-mail: sachintalwar@hotmail.com).

0022-5223/\$36.00

Copyright $₫ 2018$ Published by Elsevier Inc. on behalf of The American Association for Thoracic Surgery

https://doi.org/10.1016/j.jtcvs.2018.09.140
Since the understanding of the peculiar properties of the pediatric myocardium compared with that of adults,

Scanning this QR code will take (4) you to the article title page to access supplementary information. To view the AATS Annual Meeting Webcast, see the URL next to the webcast thumbnail.

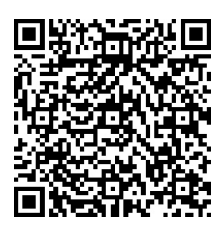




$$
\begin{aligned}
& \text { Abbreviations and Acronyms } \\
& \text { AOCX }=\text { aortic cross-clamp } \\
& \mathrm{CI}=\text { cardiac index } \\
& \mathrm{CP}=\text { cardioplegia } \\
& \mathrm{CPB}=\text { cardiopulmonary bypass } \\
& \mathrm{DN}=\text { del Nido } \\
& \text { HTK = histidine-tryptophan-ketoglutarate } \\
& \text { ICU = intensive care unit } \\
& \text { IL-6 = interleukin-6 } \\
& \text { IS }=\text { inotropic score } \\
& \text { LCOS = low cardiac output syndrome } \\
& \mathrm{RA}=\text { right atrium } \\
& \text { TAP }=\text { transannular patch } \\
& \mathrm{TNF}=\text { tumor necrosis factor } \\
& \text { TOF }=\text { tetralogy of Fallot } \\
& \text { Trop-I }=\text { troponin-I }
\end{aligned}
$$

pediatric myocardial protection strategies have evolved with the aim of allowing the surgeon enough time to perform an uninterrupted repair with preservation of myocardial function. ${ }^{2}$ Along with hypothermia and adequate venting of the heart, cardioplegia (CP) forms the most important component of any myocardial protection strategy. Debate over single dose versus multidose CP has been ongoing with proponents of either strategy. ${ }^{2}$ In a previous study, we showed the superiority of a single dose of del Nido (DN) CP over the traditional St Thomas CP. ${ }^{3}$ Histidine-tryptophan-ketoglutarate (HTK), first described by Bretschneider in 1975 is an organ preservation solution that might offer myocardial protection lasting up to 3 hours after administration of a single dose. ${ }^{4}$ However, there are no studies that have compared DN CP with HTK CP in patients undergoing surgery for congenital cyanotic heart disease. Because tetralogy of Fallot (TOF) is the most common congenital cyanotic heart disease in our surgical practice, this randomized controlled trial was performed to compare the efficacy of 2 long-acting $\mathrm{CP}$ solutions in pediatric patients undergoing intracardiac repair of TOF.

\section{METHODS}

One hundred patients, 12 years of age or younger, undergoing elective repair of TOF by a single surgical team between July 2017 and January 2018 at All India Institute of Medical Sciences, New Delhi were recruited for the study. The study protocol was duly approved by the institutional ethics committee and was registered with clinical trial registry of India (CTRI/2017/ 07/009067). Detailed informed consent was obtained from legally authorized representatives of all patients enrolled for the study. Criteria for exclusion were surgeries with aortic cross-clamp (AOCX) time $<45$ minutes, emergency surgeries, syndromic patients, patients with associated illnesses, or patients with preoperative neurological defects and syndromes.

\section{Sample Size Calculation}

For the purpose of sample size calculation, the primary outcome parameter was cardiac index (CI). Secondary outcome parameters were surrogates of myocardial protection like inotropic score (IS), cardiac enzyme release, presence of ventricular arrhythmias post cross-clamp release, presence of low cardiac output syndrome (LCOS), inflammatory marker assay, and ultrastructural changes as seen on electron microscopy. The sample size determined by us was as in our previous study on DN CP. ${ }^{3}$ DN being the common arm with similar outcomes of earlier study, we retained the same sample size for this study. Using that protocol, 44 patients were needed in each group to show this difference to be statistically significant in a 2 -sided test with $5 \% \alpha$ error and $80 \%$ power. Giving an allowance for attrition, a sample size of 50 was chosen in each group. A randomization list was generated using nQuery advisor version 7.0 (Statistical Solutions, Saugus, Mass) with a variable block size. This randomization sequence was transferred to sealed envelopes, which were opened just before assembling the cardiopulmonary bypass (CPB) circuit.

\section{Anesthesia Technique}

Standardized anesthesia technique was used in all patients. Intravenous induction with ketamine $2 \mathrm{mg} / \mathrm{kg}$, fentanyl $2 \mu \mathrm{g} / \mathrm{kg}$ and rocuronium $1 \mathrm{mg} /$ $\mathrm{kg}$ were used. Sevoflurane with air and oxygen were used for maintenance to maintain minimum alveolar concentration of $0.8-1$. Midazolam $0.1 \mathrm{mg} /$ $\mathrm{kg}$, fentanyl $0.1 \mu \mathrm{g} / \mathrm{kg}$, and vecuronium $0.1 \mathrm{mg} / \mathrm{kg}$ were used intermittently. Dobutamine $5 \mu \mathrm{g} / \mathrm{kg} / \mathrm{min}$ and sodium nitroprusside $0.5 \mu \mathrm{g} / \mathrm{kg} / \mathrm{min}$ were started electively in all patients upon rewarming before termination of $\mathrm{CPB}$ and titrated subsequently. Hypotension was managed by optimizing fluid status and/or by infusion of noradrenaline infusion $(0.05 \mu \mathrm{g} / \mathrm{kg} /$ $\mathrm{min})$ or dopamine $(5 \mu \mathrm{g} / \mathrm{kg} / \mathrm{min})$ or adrenaline $(0.05 \mu \mathrm{g} / \mathrm{kg} / \mathrm{min})$.

\section{Determination of CI}

The $\mathrm{CI}$ in our study was measured with an electrical cardiometry device, ICON monitor (ICON Osypka Medical GmBH, Berlin, Germany). This device has been shown to be a reliable and noninvasive method comparable with Fick's thermo dilution method in patients undergoing cardiac catheterization for congenital heart defects. ${ }^{5,6}$ Previous studies from our institute have shown that this modality is an acceptable alternative to invasive monitoring in adults undergoing coronary artery bypass surgery ${ }^{7}$ and it has been used by us earlier in the pediatric population ${ }^{3,8}$ and its merits and demerits have been described. ${ }^{3,8}$ After induction of anesthesia, 4 electrodes for the ICON monitor (ICON Osypka Medical GmBH) were placed. Two electrodes were placed on the left side of neck one below the other, the third on the left mid axillary line at the level of xiphisternum and the fourth $2 \mathrm{~cm}$ below the third. In infants with a short neck, the first one was placed on the forehead, second one on the left side of neck, third one on the left midaxillary line at the level of the xiphisternum, and the fourth one on the left femoral region. The first reading of $\mathrm{CI}$ was taken at the time of skin incision and was considered as baseline. The second reading CI was taken 30 minutes after termination of $\mathrm{CPB}$, just before closing the sternum. The next $2 \mathrm{CI}$ readings were taken in the intensive care unit (ICU) after 6 and 24 hours of termination of $\mathrm{CPB}$.

\section{CPB Strategy, CP, and Surgical Technique}

The CPB circuit was primed with fresh blood as per standard guidelines with or without crystalloid, Plasmalyte A (Baxter Healthcare, Toongabie, Australia), and heparin, mannitol, and sodium bicarbonate. All operations were conducted via a standard median sternotomy. After placing the aortic purse-string suture, heparin was administered at 3-4 mg/kg and CPB was initiated after the activated clotting time was $>480$ seconds. CPB was carried out at flow rates of $150-200 \mathrm{~mL} / \mathrm{kg} / \mathrm{min}$. Systemic cooling was initiated immediately after commencement of $\mathrm{CPB}$ at the rate of $1^{\circ} \mathrm{C}$ per minute to a target temperature of $28^{\circ} \mathrm{C}$.

Base solution of DN CP was made by our perfusionists by mixing $1 \mathrm{~L}$

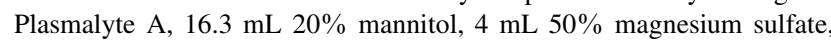
$13 \mathrm{~mL} 8.4 \%$ sodium bicarbonate, $13 \mathrm{~mL} 2 \mathrm{mEq} / \mathrm{mL}$ potassium chloride, 
and $13 \mathrm{~mL} 1 \%$ lidocaine. The osmolality of this solution is $294 \mathrm{mOsm} / \mathrm{kg}$. Final CP that was delivered to the patient consisted of a mixture of 1 part of the patient's blood drawn from the CPB circuit after CPB had been established and 4 parts of the base CP solution. A single dose of $20 \mathrm{~mL} / \mathrm{kg} \mathrm{DN}$ $\mathrm{CP}$ was administered at a pressure of $60-100 \mathrm{~mm} \mathrm{Hg}$ and temperature of $8^{\circ} \mathrm{C}-10^{\circ} \mathrm{C}$ over 5-6 minutes. In patients receiving HTK CP, a prepacked Custodiol (Sandor Medical, Hyderabad, India) solution was used; $1 \mathrm{~L}$ of this contains $\mathrm{Na} 15 \mathrm{mmol}$, K $9 \mathrm{mmol}, \mathrm{Mg} 4 \mathrm{mmol}$, Ca $0.015 \mathrm{mmol}$, histidine $198 \mathrm{mmol}$, tryptophan $2 \mathrm{mmol}$, ketoglutarate $1 \mathrm{mmol}$, and mannitol $30 \mathrm{mmol}$. It was given at a dose of $6 \mathrm{~mL} / \mathrm{kg} / \mathrm{min}$ for 6 minutes (total $36 \mathrm{~mL} / \mathrm{kg}$ ) at a temperature of $4^{\circ} \mathrm{C}-8^{\circ} \mathrm{C}$. The osmolality of this solution is $280 \mathrm{mOsm} / \mathrm{kg}$. Topical cooling with cold saline solution was used in all patients and $\mathrm{CP}$ was not repeated unless there was electrical activity, in which case half of the previous dose was administered.

After the aorta was cross-clamped and the heart was arrested in diastole, the right atrium (RA) was opened. Ventricular septal defect was closed using a trans-RA route with a Dacron patch. Infundibular resection was attempted using a trans-RA route. Adequacy of resection was checked by sizing with a Hegar dilator (Aesculap, Center Valley, Pa) of appropriate size as per body surface area. If needed, pulmonary artery reconstruction was performed and a transannular patch (TAP) was used after a limited right ventriculotomy. After 45 minutes of AOCX, a piece of normal-appearing muscle was excised from a septal trabeculation in the right ventricular outflow tract and was fixed in $2.5 \%$ glutaraldehyde and sent for preparation of block for electron microscopic studies. After discontinuation of $\mathrm{CPB}$, pressure in right ventricle/pressure in left ventricle values were routinely measured and a value of 0.6 for trans RA repair and 0.8 for the TAP group were accepted if the patients were hemodynamically stable and receiving minimal inotropes. Transesophageal echocardiography was performed in all patients to further confirm the adequacy of the repair and assessment of ventricular function. It was ensured in both groups that transesophageal echocardiography did not show any localized obstruction and gradient at any site. The higher pressure in right ventricle/pressure in left ventricle of 0.8 in the TAP group was accepted if there were no localized gradients to account for the effects of pulmonary regurgitation and resultant right ventricular dysfunction in this group.

As is the protocol in our institute, the hematocrit was maintained at $25 \%-30 \%$ during $\mathrm{CPB}$ and conventional ultrafiltration was performed along with addition of blood if needed to bring the hematocrit to around $45 \%$ at termination of CPB. Modified ultrafiltration was not performed in any patient. Using this protocol, the conventional ultrafiltration times are expected to be higher in the HTK group because it is devoid of blood and its dose is higher than that of the DN solution.

$\mathrm{CPB}$ time, AOCX time, time taken for arrest after $\mathrm{CP}$, any cardiac activity on clamp, followed by time taken for activity after cross-clamp release and any ventricular arrhythmia post clamp release were noted. Our perfusionists noted the amount of $\mathrm{CP}$ given, priming volume, volume of ultrafiltrate, and electrolyte status during CPB.

\section{Postoperative ICU Management}

All patients were transferred to the cardiac surgical ICU and managed by a separate cardiac surgery and intensive care team who were blinded to the type of the CP administered during the operation. Surgical decisions were left to the discretion of the operating surgical team who was aware of the $\mathrm{CP}$ used. All patients were ventilated initially in pressure regulated volume control mode with tidal volume of $7 \mathrm{~mL} / \mathrm{kg}$, and positive end expiratory pressure of $5 \mathrm{~mm} \mathrm{Hg}$. Weaning mode was used only after hemodynamics were optimized and there were no signs of low cardiac output and bleeding. ISs were calculated and recorded for the first 4 days: IS for the first 24 hours, from the 25 th until 48 hours, from the 49th until 72 hours. and from the 73rd until 96 hours. To calculate the IS, the vasoactive inotropic scoring system was used:

IS $=$ dopamine dose $(\mu \mathrm{g} / \mathrm{kg} / \mathrm{min})+$ dobutamine dose $(\mu \mathrm{g} / \mathrm{kg} /$ min $)+100 \times$ epinephrine dose $(\mu \mathrm{g} / \mathrm{kg} / \mathrm{min})+10 \times$ milrinone dose $(\mu \mathrm{g} / \mathrm{kg} / \mathrm{min})+10,000 \times$ vasopressin dose $(\mathrm{U} / \mathrm{kg} / \mathrm{min})+100 \times$ norepinephrine dose $(\mu \mathrm{g} / \mathrm{kg} / \mathrm{min}){ }^{9}$

Postoperative hemodynamic data along with time to peripheral warming, duration of mechanical ventilation, and duration of ICU and hospital stay were recorded. LCOS was defined by delayed time to peripheral warming, nonpalpable lower limb distal pulses, urine output $<0.5 \mathrm{~mL} /$ $\mathrm{kg} / \mathrm{h}$ for $>3$ hours, increasing acidosis and lactate levels, or a combination of these factors. Patients were shifted out of the ICU after weaning from all inotropes. They were discharged from the hospital after an echocardiographic confirmation of an adequate repair and a favorable electrical rhythm on electrocardiogram.

\section{Biochemical Analysis}

Three venous blood samples were collected, the first at the time of skin incision, the second 30 minutes after termination of $\mathrm{CPB}$, and the third in the ICU, 24 hours after termination of $\mathrm{CPB}$. These samples were centrifuged and the serum was stored at $-80^{\circ} \mathrm{C}$ to preserve the enzyme system. Blood samples were analyzed for interleukin-6 (IL-6), tumor necrosis factor (TNF)- $\alpha$, and troponin I (Trop-I) by a laboratory technician blinded to the type of CP that had been used. Serum levels of IL-6, TNF- $\alpha$, and Trop-I were determined with commercially available enzyme linked immunosorbent assay kits according to the manufacturer guidelines.

\section{Electron Microscopic Studies}

Electron microscopic studies were performed on the resected myocardial specimen. The tissue samples were taken 45 minutes after applying the AOCX and were fixed in $2.5 \%$ glutaraldehyde solution for 12 hours. The samples were then transferred into 0.1 molar cacodylate buffer $(\mathrm{pH} 7.3)$, cooled to $4^{\circ} \mathrm{C}$, and prepared for electron microscopy. Ultrathin sections of $70 \mathrm{~nm}$ were prepared on copper grids. The slides were stained with uranyl acetate and lead citrate and were examined using an electron microscope (TECNAI-20 HR-Transmission electron microscope 200 kV; FEI Holland, Hillsboro, Ore). A modified scoring system was adopted from heart injury scoring. Scoring was done for the subcellular ultrastructural changes occurring in the nucleus, mitochondria, and sarcoplasmic reticulum. ${ }^{10}$ Loss of glycogen stores, intracellular edema, and myofibrillar arrangements were studied in addition to heart injury scoring parameters. Scores of 0-3 were given for each structure denoting absent, mild moderate, and severe changes, respectively. Quantitative evaluation of ultrastructural changes was performed by a cardiac pathologist who was blinded to the CP strategy.

\section{Statistical Analysis}

Statistical analysis was performed using STATA software (version 14.0; StataCorp LP, College Station, Tex). Data are presented as mean and standard deviation with median and interquartile range for continuous variables and $\mathrm{n}(\%)$ for categorical variables. The continuous variables that were normally distributed were compared between the HTK and DN group using Student $t$ test and those that had skewed distribution were compared using the nonparametric Wilcoxon rank sum test. A robust mixed effect modeling with unstructured covariance structure was carried out taking patient's effect as random. A group versus time interaction was tested for CI and IS. The timewise trends of CI and IS of the 2 groups are plotted along with $95 \%$ confidence intervals on the basis of 500 bootstrap samples. For outcomes that were not the prime focus of interest or were not significant in simple analysis, this analysis was not performed. $P$ value $<.05$ was considered statistically significant.

\section{RESULTS}

Demographic characteristics including age, sex ratio, weight, body surface area, and operative procedures are shown in Table 1. There was no significant difference 
TABLE 1. Description of the demographic characteristics and operative procedures of patients in the study groups

\begin{tabular}{lcc}
\hline \multicolumn{1}{c}{ Characteristic } & DN $(\mathbf{n}=\mathbf{5 0})$ & HTK $(\mathbf{n}=\mathbf{5 0})$ \\
\hline Age, $\mathrm{y}$ & & \\
Mean \pm SD & $4.45 \pm 3.23$ & $5.10 \pm 2.78$ \\
Median (IQR) & $3.5(1.9-6.75)$ & $4.50(2.86-7.18)$ \\
Female sex, $\mathrm{n}(\%)$ & $14(28)$ & $17(34)$ \\
Mean weight, kg & & \\
Mean \pm SD & $14.2 \pm 8.38$ & $14.02 \pm 8.44$ \\
Median (IQR) & $12(8-18)$ & $11(8.5-18)$ \\
BSA, m ${ }^{2}$ & & \\
Mean \pm SD & $0.62 \pm 0.26$ & $0.60 \pm 0.22$ \\
Median (IQR) & $0.57(0.42-0.74)$ & $0.53(0.44-0.74)$ \\
Operative procedure, n (\%) & & \\
Trans RA ICR & $37(75)$ & $38(76)$ \\
Trans RA ICR and TAP & $10(20)$ & $5(10)$ \\
Trans RA ICR and LPA plasty & $3(5)$ & $7(14)$ \\
\hline
\end{tabular}

$D N$, Del Nido; $H T K$, histidine-tryptophan-ketoglutarate; $S D$, standard deviation; $I Q R$, interquartile range; $B S A$, body surface area; $R A$, right atrium; $I C R$, intracardiac repair; $T A P$, trans annular patch; $L P A$, left pulmonary artery.

between these parameters. The degree of preoperative cyanosis, ventricular hypertrophy, and function was similar in both groups, hence they are not mentioned in the table. There was no difference in the need for TAP or pulmonary artery reconstruction in both groups. Intra- and postoperative assessment using echocardiography revealed normal biventricular function and no residual defect in either group.

Intraoperative characteristics are shown in Table 2. There was no significant difference between the CPB and AOCX times between the 2 groups. Mean time taken for complete electromechanical arrest of the heart from the commencement of CP delivery and the time for return of activity after AOCX release were significantly higher in HTK group $(P=.01$ and $P<.001$, respectively). There was also increased incidence of ventricular arrhythmias after aortic cross-clamp release $(P=.029)$ and a greater number of patients had electrical activity during the arrest period (but not sufficient for the heart to beat, hence, repeated administration was not needed) with the use of HTK CP $(P=.045)$. The ventricular arrhythmias were in the form of premature ventricular contractions and ventricular tachycardia in the HTK group. However, these subsided with CPB support. Ventricular fibrillation requiring defibrillation was not observed. Time taken for return to normal sinus rhythm was longer in the HTK group $(P<.001)$. The mean amount of $\mathrm{CP}$ required for each patient and the cost of $\mathrm{CP}$ per patient was significantly higher for the HTK group ( $P=.002$ and $P<.001$, respectively). This is primarily related to the dosing protocol for the 2 groups, in which only a dose of $20 \mathrm{~mL} / \mathrm{kg}$ was administered in the $\mathrm{DN}$ group and $6 \mathrm{~mL} / \mathrm{kg} / \mathrm{min}$ (total $36 \mathrm{~mL} / \mathrm{kg}$ ) was needed in the HTK group. Because of these reasons, and because HTK is asanguninous, mean intraoperative hematocrit during $\mathrm{CPB}$ was less in the HTK group compared with the DN group $(P=.004)$. Volume of ultrafiltrate, priming volume, blood transfusion, and values of serum potassium at various points during the operation were not significantly different.

Distribution of postoperative variables are shown in Table 3. Variables that are surrogates of good myocardial protection are compared. Time for peripheral warming to $32^{\circ} \mathrm{C}$ was significantly less in the $\mathrm{DN}$ group $(P=.023)$, so also were the mean ICU stay $(P=.05)$ and hospital stay $(P<.001)$. More patients developed LCOS in the ICU in the HTK group ( 2 vs $9 ; P=.025$ ). There was 1 death in each group. Death in the DN group was due to sepsis and later septic shock and 1 in HTK group was due to fulminant pulmonary hemorrhage and acute respiratory distress syndrome.

Figures E1 and E2 compare the cardiac indices $\left(\mathrm{L} / \mathrm{min} / \mathrm{m}^{2}\right)$ and ISs at various time intervals. Cardiac indices were measured preoperatively, and at 30 minutes, 6 hours, and 24 hours after termination of CPB. Cardiac indices before $\mathrm{CPB}$ were comparable between the 2 groups. Although the cardiac indices decreased after termination of CPB from pre-CPB values in both groups, they were lower in the HTK compared with the DN group at the first reading after $\mathrm{CPB}$, but were not statistically significant. However, the values were significantly higher in the DN group at 6 and 24 hours after termination of CPB $(P=.005$ and $P<.001$, respectively). Mixed effect analysis indicated a significant group versus time interaction in CI values over time $(P<.001)$. This is illustrated in Figure 1 where the CI started showing an increase with time in the DN group, which is not the same as that observed in the HTK group. In view of the significant interaction between groups and time, an average of $\mathrm{CI}$ between the 2 groups is not meaningful. So, analysis at each time was performed, which was significant at every time point between the 2 groups (Table 4 ).

The IS pattern also illustrated better recovery of myocardial function in the DN group. The mean IS at the end of the first 24 hours, in the second 24 hours, and in the third and fourth 24 hours was significantly lower in the DN group ( $P=.021, P=.036, P=.026$, and $P=.008$, respectively). Mixed effect analysis indicated an average difference of ISs of 7.9 (95\% confidence interval, $2.131-3.63 ; P<.001)$ more in the HTK group at any time. Group versus time interaction (Figure 2) was of borderline significance $(P=.054)$ This indicates that ISs in the DN group are uniformly less over time compared with the HTK group.

Trop-I level and inflammatory markers IL- 6 and TNF- $\alpha$ (Figures 3-5) were compared between the 2 groups at various time points (Table 4). There was no significant difference in the pre-CPB Trop-I level values between the 2 groups. Post-CPB, there was a rise in the values in each group but comparisons between the groups were not significant. A decrease in Trop-I values after 24 hours was greater 
TABLE 2. Distribution of intraoperative characteristics between the DN and HTK groups

\begin{tabular}{|c|c|c|c|}
\hline Characteristic & DN $(\mathbf{n}=\mathbf{5 0})$ & HTK $(\mathbf{n}=\mathbf{5 0})$ & $P$ value \\
\hline $\begin{array}{l}\text { CPB time, min } \\
\text { Mean } \pm \text { SD } \\
\text { Median (IQR) }\end{array}$ & $\begin{array}{r}126.04 \pm 15.66 \\
125.50(113-133)\end{array}$ & $\begin{array}{c}128.92 \pm 16.83 \\
127(116-138)\end{array}$ & .09 \\
\hline $\begin{array}{l}\text { AOCX time, } \min \\
\text { Mean } \pm \text { SD } \\
\text { Median }(\mathrm{IQR})\end{array}$ & $\begin{array}{l}85.04 \pm 13.03 \\
82.0(72-92)\end{array}$ & $\begin{array}{l}87.06 \pm 15.91 \\
85.50(75-94)\end{array}$ & .07 \\
\hline $\begin{array}{l}\text { Amount of cardioplegia, mL } \\
\text { Mean } \pm \text { SD } \\
\text { Median (IQR) }\end{array}$ & $\begin{array}{r}364.90 \pm 234.99 \\
300(190-425)\end{array}$ & $\begin{array}{c}505.2 \pm 300.31 \\
400(310-650)\end{array}$ & .002 \\
\hline $\begin{array}{l}\text { Volume of ultrafiltration, } \mathrm{mL} \\
\text { Mean } \pm \mathrm{SD} \\
\text { Median (IQR) }\end{array}$ & $\begin{array}{c}592.00 \pm 296.70 \\
500(400-725)\end{array}$ & $\begin{array}{c}565.00 \pm 283.61 \\
600(300-700)\end{array}$ & .989 \\
\hline $\begin{array}{l}\text { Time of hypothermia, min } \\
\text { Mean } \pm \text { SD } \\
\text { Median (IQR) }\end{array}$ & $\begin{array}{c}81.32 \pm 11.28 \\
78(75-88)\end{array}$ & $\begin{array}{c}91.60 \pm 16.10 \\
57.00(80-100)\end{array}$ & $<.001$ \\
\hline $\begin{array}{l}\text { Time taken for arrest, } \mathrm{s} \\
\text { Mean } \pm \mathrm{SD} \\
\text { Median }(\mathrm{IQR})\end{array}$ & $\begin{array}{c}25.08 \pm 9.03 \\
25(18-32)\end{array}$ & $\begin{array}{c}34.24 \pm 15.39 \\
31(24-37)\end{array}$ & .01 \\
\hline $\begin{array}{l}\text { Time taken for return of activity, s } \\
\text { Mean } \pm \text { SD } \\
\text { Median (IQR) }\end{array}$ & $\begin{array}{l}35.74 \pm 16.45 \\
35.50(20-50)\end{array}$ & $\begin{array}{l}54.66 \pm 16.10 \\
54.00(43-66)\end{array}$ & $<.001$ \\
\hline $\begin{array}{l}\text { Time taken for NSR, } \mathrm{s} \\
\text { Mean } \pm \mathrm{SD} \\
\text { Median (IQR) }\end{array}$ & $\begin{array}{c}107.60 \pm 59.16 \\
90.0(73-132)\end{array}$ & $\begin{array}{r}179.84 \pm 77.09 \\
177.5(124-210)\end{array}$ & $<.001$ \\
\hline $\begin{array}{l}\text { Time for rewarming, min } \\
\text { Mean } \pm \text { SD } \\
\text { Median (IQR) }\end{array}$ & $\begin{array}{c}13.42 \pm 6.11 \\
12(9-16)\end{array}$ & $\begin{array}{c}18.84 \pm 9.76 \\
15(11-25)\end{array}$ & .004 \\
\hline Activity during arrest, $\mathrm{n}(\%)$ & $2(4)$ & $8(16)$ & .045 \\
\hline Ventricular arrhythmia post clamp release, n (\%) & $10(20)$ & $20(40)$ & .029 \\
\hline Defibrillation, n (\%) & $7(14)$ & $8(16)$ & .78 \\
\hline $\begin{array}{l}\text { Priming volume, } \mathrm{mL} \\
\text { Mean } \pm \mathrm{SD} \\
\text { Median (IQR) }\end{array}$ & $\begin{array}{r}902.00 \pm 265.72 \\
900(700-1100)\end{array}$ & $\begin{array}{r}955.00 \pm 245.00 \\
950(800-1100)\end{array}$ & .30 \\
\hline $\begin{array}{l}\text { Total IVF, } \mathrm{mL} \\
\text { Mean } \pm \mathrm{SD} \\
\text { Median }(\mathrm{IQR})\end{array}$ & $\begin{array}{c}334.00 \pm 209.26 \\
250(160-500)\end{array}$ & $\begin{array}{c}385.20 \pm 216.01 \\
375(200-500)\end{array}$ & .20 \\
\hline $\begin{array}{l}\text { Blood transfusion, } \mathrm{mL} \\
\text { Mean } \pm \mathrm{SD} \\
\text { Median (IQR) }\end{array}$ & $\begin{array}{r}245.00 \pm 101.00 \\
250(200-300)\end{array}$ & $\begin{array}{c}224.00 \pm 76.4 \\
200(200-300)\end{array}$ & .33 \\
\hline $\begin{array}{l}\text { Lowest intraoperative hematocrit, \% } \\
\text { Mean } \pm \text { SD } \\
\text { Median (IQR) }\end{array}$ & $\begin{array}{r}28.7 \pm 3.0 \\
28.0(27-31)\end{array}$ & $\begin{array}{l}27.02 \pm 2.64 \\
26.0(25-29)\end{array}$ & .004 \\
\hline
\end{tabular}

$D N$, Del Nido; $H T K$, histidine-tryptophan-ketoglutarate; $C P B$, cardiopulmonary bypass; $S D$, standard deviation; $I Q R$, interquartile range; $A O C X$, aortic cross-clamp; $N S R$, normal sinus rhythm; $I V F$, intravenous fluids.

in the DN group and their mean values after 24 hours were significantly lower for the DN group $(P<.001)$.

Differences in serum inflammatory markers were not significant between the groups at any time point. In both groups, there was maximum increase 30 minutes after termination of $\mathrm{CPB}$ and decrease after 24 hours but not below the pre-CPB values.

Electron microscopic features in the 2 groups according to modified heart injury scoring are shown in Table 5 and Figure 6. There were no statistically significant differences 
TABLE 3. Distribution of postoperative characteristics in the DN and HTK groups

\begin{tabular}{|c|c|c|c|}
\hline Characteristic & $\begin{array}{c}\text { DN } \\
(\mathbf{n}=\mathbf{5 0})\end{array}$ & $\begin{array}{c}\text { HTK } \\
(\mathbf{n}=\mathbf{5 0})\end{array}$ & $\begin{array}{c}P \\
\text { value }\end{array}$ \\
\hline \multicolumn{4}{|l|}{ Time for peripheral warming, $\mathrm{h}$} \\
\hline Mean \pm SD & $4.04 \pm 2.96$ & $5.8 \pm 5.95$ & \\
\hline Median (IQR) & $3(2.75-5)$ & $3.75(3-4.75)$ & .023 \\
\hline \multicolumn{4}{|l|}{ Mechanical ventilation, $\mathrm{h}$} \\
\hline Mean \pm SD & $7.37 \pm 5.17$ & $10.92 \pm 12.05$ & \\
\hline Median (IQR) & $5.75(4.2-8.3)$ & $8(4-10)$ & .006 \\
\hline LCOS, n (\%) & $2(4)$ & $9(18)$ & .025 \\
\hline Lactate level after 24 hours & & & .51 \\
\hline Mean \pm SD & $1.6 \pm 1.7$ & $2.45 \pm 1.42$ & \\
\hline Median (IQR) & $1.7(1.23-4.0)$ & $2.3(1.5-4.5)$ & \\
\hline \multicolumn{4}{|l|}{ Mean ICU stay, h } \\
\hline Mean \pm SD & $38.70 \pm 16.00$ & $43.45 \pm 16.42$ & \\
\hline Median (IQR) & $40.5(24-45)$ & $40(38-43)$ & .05 \\
\hline \multicolumn{4}{|l|}{ Hospital stay, d } \\
\hline Mean \pm SD & $5.94 \pm 0.97$ & $6.7 \pm 1.03$ & \\
\hline Median (IQR) & $6(5-7)$ & $7(6-7)$ & $<.001$ \\
\hline 30-Day mortality, n (\%) & $1(2.0)$ & $1(2.0)$ & 1 \\
\hline
\end{tabular}

in the mean scores obtained for nuclear changes, mitochondrial, and sarcoplasmic reticulum changes. However, the glycogen depletion and myofibrillar disarray scores were lower in the DN group compared with the HTK group

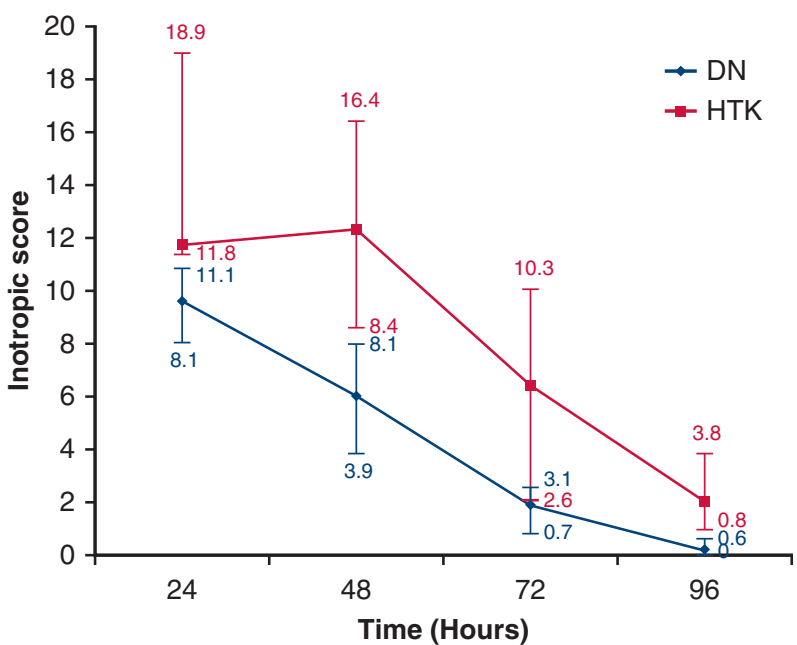

FIGURE 1. Timewise trend of inotropic score $(I S)$ of the del Nido $(D N)$ and histidine-tryptophan-ketoglutarate (HTK) group. The means observed at each time point in the 2 groups are indicated. The timewise trends of IS of the 2 groups are plotted along with $95 \%$ confidence intervals on the basis of 500 bootstrap samples. Mixed effect analysis indicated an average difference of IS of 7.9 (95\% confidence interval, $2.13-13.63 ; P<.001)$ more in the HTK group at any time. Group versus time interaction was of borderline significance $(P=.054)$. This indicates that inotropic scores in the DN group are uniformly less over time compared with the HTK group.
TABLE 4. Distribution of troponin I and inflammatory markers between DN and HTK groups at 3 different intervals

\begin{tabular}{|c|c|c|c|}
\hline Inflammatory marker & $\begin{array}{c}\text { DN } \\
(\mathbf{n}=\mathbf{5 0})\end{array}$ & $\begin{array}{c}\text { HTK } \\
(n=50)\end{array}$ & $\begin{array}{c}P \\
\text { value }\end{array}$ \\
\hline \multicolumn{4}{|l|}{ Troponin I, ng/mL } \\
\hline \multicolumn{4}{|l|}{ Pre-CPB } \\
\hline Mean \pm SD & $0.70 \pm 0.47$ & $0.71 \pm 0.39$ & .67 \\
\hline Median (IQR) & $0.64(0.42-0.90)$ & $0.63(0.46-0.93)$ & \\
\hline \multicolumn{4}{|l|}{ Post-CPB } \\
\hline Mean \pm SD & $6.68 \pm 5.30$ & $9.88 \pm 8.31$ & .093 \\
\hline Median (IQR) & $5.86(3.83-7.81)$ & $6.39(4.46-10.05)$ & \\
\hline \multicolumn{4}{|l|}{24 Hours } \\
\hline Mean \pm SD & $4.19 \pm 2.91$ & $8.15 \pm 5.26$ & \\
\hline Median (IQR) & $3.76(2.94-4.76)$ & $6.39(4.46-9.86)$ & $<.001$ \\
\hline \multicolumn{4}{|l|}{ IL-6, pg/mL } \\
\hline \multicolumn{4}{|l|}{ Pre-CPB } \\
\hline Mean \pm SD & $6.30 \pm 3.56$ & $4.56 \pm 4.71$ & .12 \\
\hline Median (IQR) & $6(3-10)$ & $5(0-6.25)$ & \\
\hline \multicolumn{4}{|l|}{ Post-CPB } \\
\hline Mean \pm SD & $156.94 \pm 46.88$ & $179.94 \pm 52.89$ & .113 \\
\hline Median (IQR) & 149 (121-193) & $154.5(139-193)$ & \\
\hline \multicolumn{4}{|l|}{24 Hours } \\
\hline Mean \pm SD & $53.56 \pm 19.33$ & $72.32 \pm 39.95$ & \\
\hline Median (IQR) & $52.0(43-61)$ & $58(48.50-85.6)$ & .20 \\
\hline \multicolumn{4}{|l|}{$\mathrm{TNF}-\alpha(\mu \mathrm{g} / \mathrm{mL})$} \\
\hline \multicolumn{4}{|l|}{ Pre-CPB } \\
\hline Mean \pm SD & $2.82 \pm 2.49$ & $2.12 \pm 2.0$ & .077 \\
\hline Median (IQR) & $4(0-5)$ & $3(0-4)$ & \\
\hline \multicolumn{4}{|l|}{ Post-CPB } \\
\hline Mean \pm SD & $61.90 \pm 17.53$ & $63.48 \pm 17.16$ & \\
\hline Median (IQR) & $61(52-73)$ & $65.0(46-76)$ & .65 \\
\hline \multicolumn{4}{|l|}{24 Hours } \\
\hline Mean \pm SD & $19.00 \pm 7.93$ & $22.78 \pm 12.91$ & \\
\hline Median (IQR) & $18.5(12.75-25)$ & $20.50(13.75-24)$ & .464 \\
\hline
\end{tabular}

$D N$, Del Nido; $H T K$, histidine-tryptophan-ketoglutarate; $C P B$, cardiopulmonary bypass; $S D$, standard deviation; $I Q R$, interquartile range; $I L$, interleukin; $T N F$, tumor necrosis factor.

( $P=.04, P=.04$, respectively). Cellular edema was significantly less in the DN group compared with the HTK group $(P=.02)$.

Typically, $1 \mathrm{~L}$ of DN costs USD $\$ 4.61$ whereas an equivalent amount of HTK costs USD \$184. The difference in cost of the 2 solutions is therefore statistically significant.

\section{DISCUSSION}

Despite its widespread use in Europe ${ }^{11}$ there are very few data comparing the efficacy of HTK with conventional blood or crystalloid $\mathrm{CP}$, more so in the pediatric population. There is, however, data to support the use of a single dose of $\mathrm{CP}$ in the pediatric population. ${ }^{2}$ We have also shown that single-dose DN CP is superior to $\mathrm{St}$ Thomas CP in pediatric patients. ${ }^{3}$ However, there is no randomized study comparing the long-acting $\mathrm{CP}$ solutions in children. We therefore conducted this prospective randomized control 


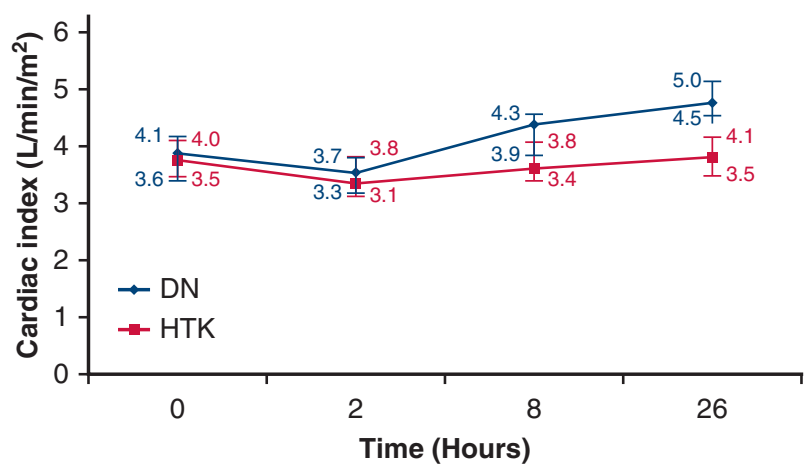

FIGURE 2. Timewise trend of cardiac index $\left(C I, \mathrm{~L} / \mathrm{min} / \mathrm{m}^{2}\right)$ of the del Nido $(D N)$ and histidine-tryptophan-ketoglutarate $(H T K)$ groups. The means observed at each time point in the 2 groups are indicated. The timewise trends of CI of the 2 groups are plotted along with $95 \%$ confidence intervals on the basis of 500 bootstrap samples. As suggested bootstrapping was done using 500 samples to obtain the CI. Mixed effect analysis showing a significant group versus time interaction in CI values over time $(P<.001)$. The CI started showing an increase with time in the DN group, which is not the same as that observed in the HTK group. In view of the significant interaction between groups and time, an average of $\mathrm{CI}$ of the 2 groups is not meaningful. So, analysis at each time was performed, which was significant at every time point for the 2 groups.

trial comparing the 2 long-acting $\mathrm{CP}$ solutions in terms of superior $\mathrm{CI}$ at various intervals postoperatively and also superiority of parameters that were surrogates of better myocardial protection. Cardiac Trop-I and serum inflammatory markers were also compared at various time points along with electron microscopic scores. Modi and colleagues stratified the effects of blood and crystalloid CP according to the presence of cyanosis. The authors suggested

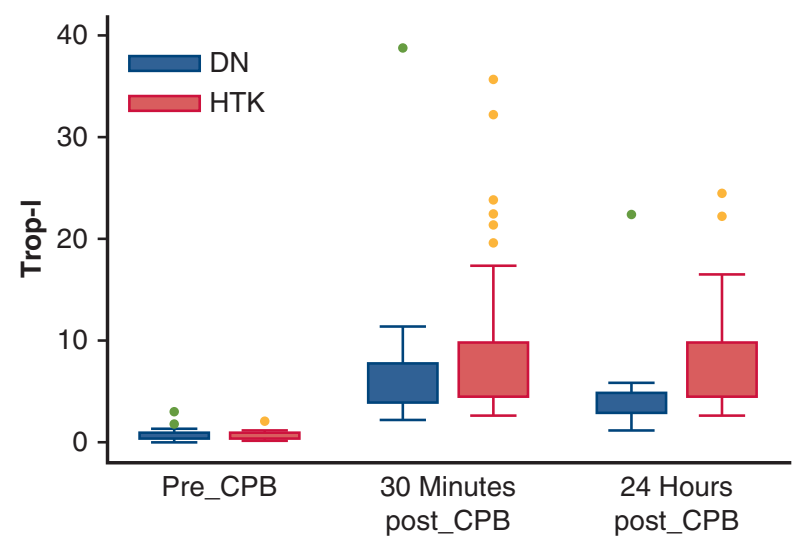

FIGURE 3. Box plot comparing troponin-I (Trop-I) levels in $\mathrm{ng} / \mathrm{mL}$ at 3 time points. There was no significant difference in the precardiopulmonary bypass (Pre_CPB) Trop-I level values between the 2 groups. After CPB (post_CBP), there was a rise in the values in each group but comparison between the groups was not significant. Decrease in Trop-I values after 24 hours was more in the del Nido $(D N)$ group and their mean values after 24 hours were significantly lower for the DN group compared with the histidine-tryptophan-ketoglutarate $(H T K)$ group $(P<.001)$.

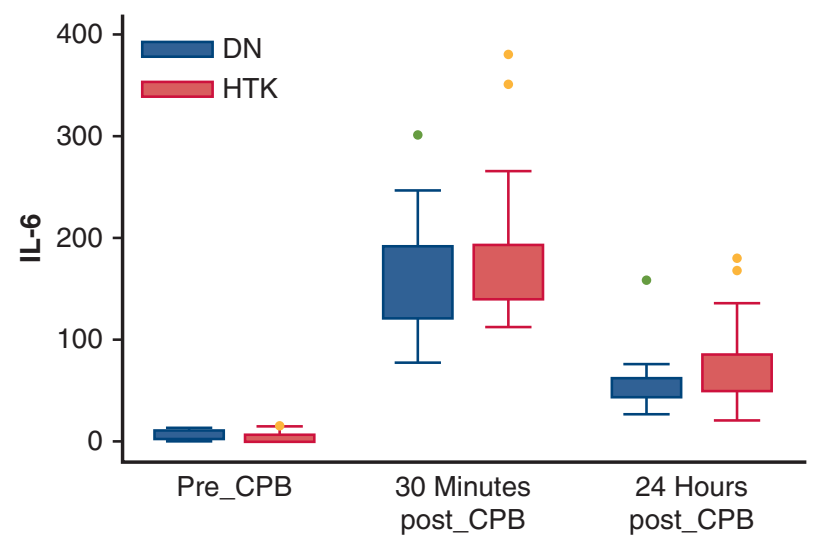

FIGURE 4. Box plot comparing serum interleukin-6 (IL-6) in $\mathrm{pg} / \mathrm{mL}$ at 3 time points of the del Nido $(D N)$ group compared with the histidinetryptophan-ketoglutarate (HTK) group. Differences in IL-6 were not significant between the groups at any of the time points. In both groups, there was maximum increase 30 minutes after termination of cardiopulmonary bypass (post_CPB) and decrease after 24 hours but not below the values before cardiopulmonary bypass $($ Pre_CPB).

that the myocardium of cyanotic pediatric patients might undergo an unintended reoxygenation injury upon commencement of $\mathrm{CPB}$, which could affect its tolerance to a subsequent period of ischemia. However, the method of CP might be less important in acyanotic patients, who tend to undergo surgery at an older age and usually require shorter AOCX times (45 minutes). ${ }^{12}$ We therefore specifically chose the cyanotic patients to identify the ideal CP strategy in the toughest subset of pediatric patients.

In our study we found that CI decreased significantly from the pre-CPB values in both groups 30 minutes after

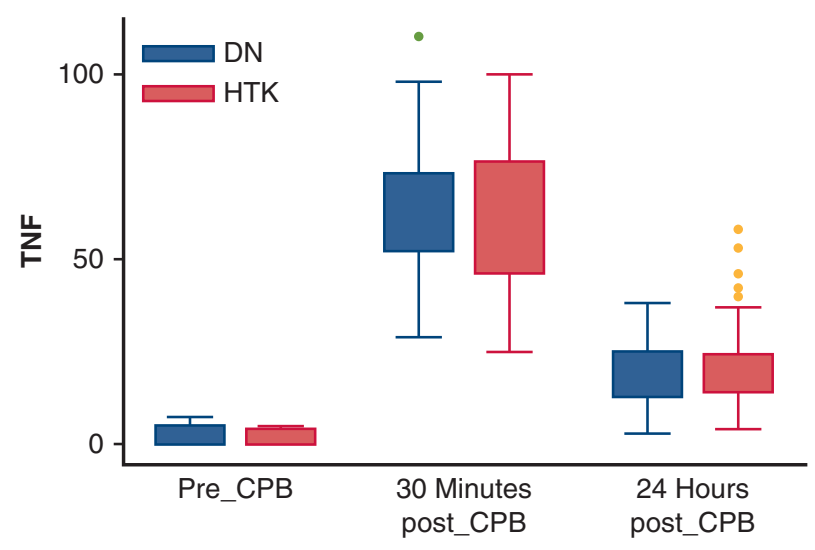

FIGURE 5. Box plot comparing serum tumor necrosis factor (TNF)- $\alpha$ levels in $\mu \mathrm{g} / \mathrm{mL}$ at 3 time points for the del Nido $(D N)$ group compared with the histidine-tryptophan-ketoglutarate $(H T K)$ group. Differences in TNF- $\alpha$ levels were not significant between the groups at any of the time points. In both groups, there was maximum increase 30 minutes after termination of cardiopulmonary bypass (post_CPB) and decrease after 24 hours but not below the values before cardiopulmonary bypass (Pre_CPB). 
TABLE 5. Electron microscopic features of the 2 groups according to the modified heart injury score

\begin{tabular}{lccc}
\hline \multicolumn{1}{c}{ Characteristic } & DN $(\mathbf{n}=\mathbf{5 0})$ & HTK $(\mathbf{n}=\mathbf{5 0})$ & $\boldsymbol{P}$ value \\
\hline Nucleus & & & \\
$\quad$ Mean \pm SD & $1.1 \pm 0.35$ & $1.1 \pm 0.37$ & \\
$\quad$ Median $(\mathrm{IQR})$ & $0(1-3)$ & $0(1-2)$ & .2 \\
Mitochondria & & & \\
$\quad$ Mean \pm SD & $2.3 \pm 0.49$ & $2.1 \pm 0.59$ & \\
$\quad$ Median (IQR) & $2(1-3)$ & $2(2-3)$ & .39 \\
Sarcoplasmic reticulum & & & \\
$\quad$ Mean \pm SD & $1.8 \pm 0.9$ & $1.9 \pm 0.7$ & \\
$\quad$ Median (IQR) & $1(2-3)$ & $2(2-3)$ & .5 \\
Myofibrillar disarray & & & .04 \\
Mean \pm SD & $1.4 \pm 0.9$ & $2.0 \pm 0.7$ & \\
Median (IQR) & $1(1-3)$ & $2(1-3)$ & \\
Glycogen stores & & & .04 \\
Mean \pm SD & $2.2 \pm 0.7$ & $2.6 \pm 0.9$ & \\
Median (IQR) & $2(1-3)$ & $2(1-3)$ & .02 \\
Cellular edema & & & \\
Mean \pm SD & $1.6 \pm 0.6$ & $2.22 \pm 0.7$ & $2(1-3)$ \\
Median (IQR) & $1(1-3)$ & & \\
\hline
\end{tabular}

$D N$, Del Nido; $H T K$, histidine-tryptophan-ketoglutarate; $S D$, standard deviation; $I Q R$, interquartile range.

termination of CPB. This observation is in concordance with observations of another study that CI decreases significantly in the immediate post bypass period and reaches a nadir anywhere between 6 and 12 hours and then rises to pre-CPB values by 24 hours, thus signifying that the myocardium requires some time to recover after cardioplegic arrest. ${ }^{13}$ The subsequent CI values at 6 and 24 hours after termination of CPB were significantly higher in the DN group compared with the HTK group, indirectly signifying better myocardial protection.

IS is a cumulative reflection of the net inotropic requirement of a patient at any point in time. ${ }^{9}$ Superior CI values in the DN group are further substantiated by the significantly lower IS in the DN group at all intervals from 24 to 96 hours and a significantly fewer number of patients in LCOS after DN CP. In fact, IS in many patients were 0 , signifying no need for inotropes and in both groups, these approached 0 after 72 hours, signifying that these are needed only in the first 72 hours after surgery. However, better preservation of myocardial function in the DN group might be because of the presence of magnesium, which antagonizes calcium, thus safeguarding the cell from the harmful effects of this ion during reperfusion. ${ }^{14,15}$ However, this observation needs to be validated further.

One can also argue the observed differences in the 2 main outcomes of CI and IS could be because of the difference in intraoperative parameters between the 2 groups as detailed in Table 2. However, we examined this possibility and found that none of the intraoperative parameters have any bearing on the groupwise differences except for the higher volume of $\mathrm{CP}$ administered in the HTK group (for reasons of correct dosage).
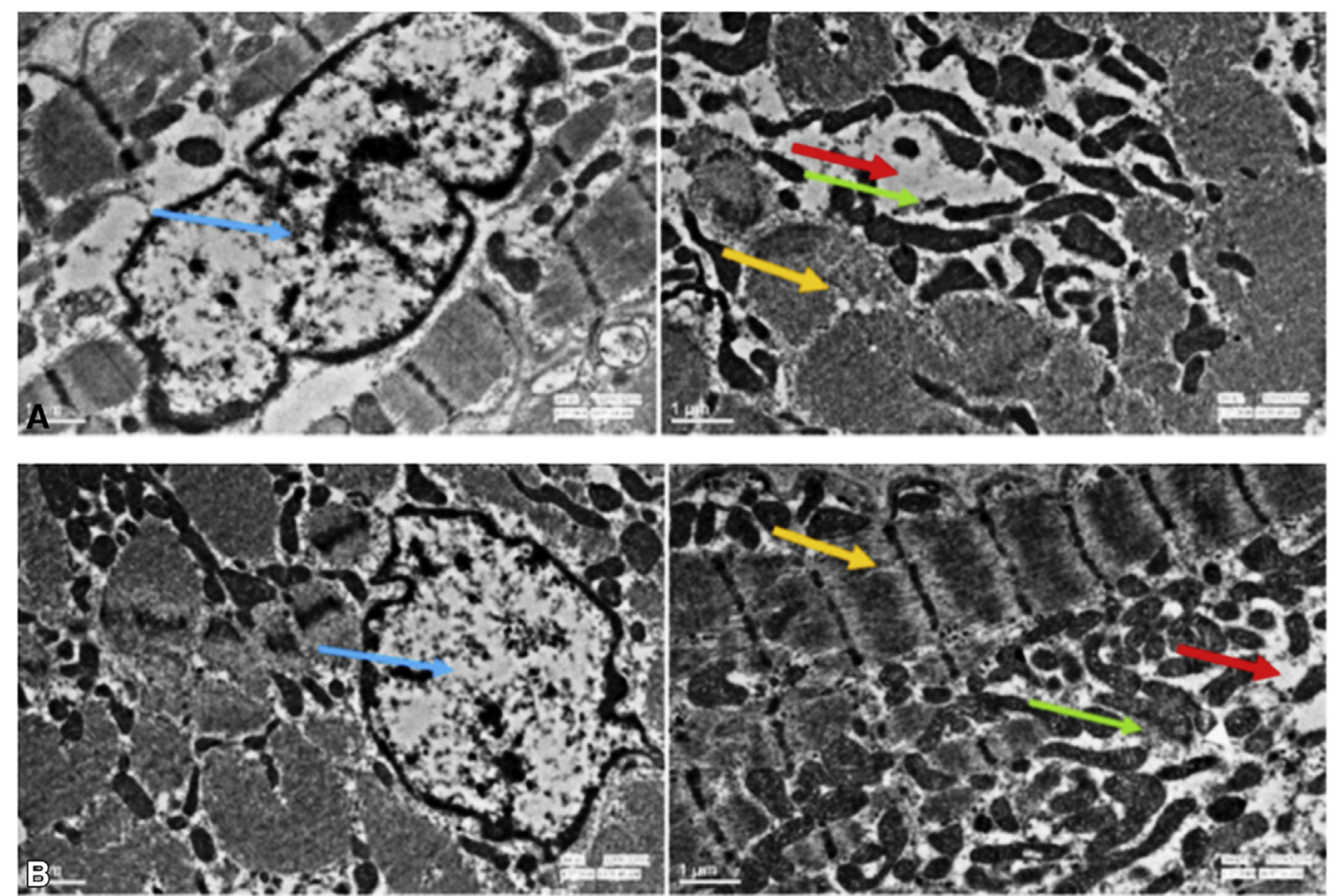

FIGURE 6. Representative electron microscopic images of myocardial tissue after 45 minutes of cross-clamp in (A) histidine-tryptophan-ketoglutarate cardioplegia and (B) del Nido cardioplegia groups. Blue arrow shows the nucleus, yellow arrows show the myofibrils, green arrows show the glycogen granules, and red arrows show the intracellular edema. 
It is a known fact that the quicker the heart arrests after AOCX, the better the preservation of the intracellular adenosine triphosphate stores. ${ }^{16}$ In our study we found that the time for achieving electromechanical arrest was significantly less with DN CP and there was a significantly fewer number of patients with activity during the arrest period. Post AOCX release, a significantly fewer number of patients had ventricular arrhythmia in the DN group. Time taken for return to normal sinus rhythm was also less with DN CP. This quick arrest and better maintenance of membrane stability with DN CP can be attributed to lidocaine, which inhibits the fast sodium channels in the myocardium, thus stabilizing the membrane against sodium currents, which might trigger spikes of depolarization and thus arrhythmias. ${ }^{17}$

Long AOCX time is an independent risk factor for increased duration of mechanical ventilation, higher incidence of LCOS, renal complications, and immediate postoperative mortality. ${ }^{18}$ In this subset of patients, our mean clamp time was $>80$ minutes in both groups and there was no significant difference between them, thus removing the confounding effect of the previously mentioned factors on postoperative findings. Hence, the findings of significantly less peripheral rewarming time, duration of mechanical ventilation, and ICU and hospital stay can be attributed to better myocardial recovery with DN CP.

Trop-I levels strongly correlate with the degree of myocardial injury that occurs during ischemia-induced cardiac arrest. ${ }^{19}$ Importantly, Trop-I 24-hour levels have been shown to predict short-term and long-term mortality, even after adjusting for complexity of the operation. ${ }^{20}$ In our study we found that Trop-I values were significantly lower in the DN group at 24 hours, thus substantiating better myocardial protection with DN. Bojan and colleagues, in a study comparing HTK with warm blood CP in transposition of great arteries patients, also reported higher postoperative troponin concentrations in the HTK group before and after matching for coronary anatomy. ${ }^{21}$

Ideally, to know the contribution of injured myocardium in releasing inflammatory markers, an assessment of coronary sinus IL- 6 and TNF- $\alpha$ should be done. But because of logistic considerations this was not possible in our setup and hence we relied on their serum markers as a surrogate. There was no significant difference between the levels of these inflammatory cytokines at any time point in our study. CPB is an independent trigger of the inflammatory cascade ${ }^{22}$ and hence the contribution of $\mathrm{CP}$ to inflammatory marker levels could not be clarified from our findings.

Ultrastructural changes in the myocardium during ischemic cardioplegic arrest indicate the effect of $\mathrm{CP}$ in subcellular organelles and contractile apparatus, which ultimately reflect as myocardial performance in the postoperative period. ${ }^{3}$ Our findings of better preservation of glycogen stores with DN can be due to quick arrest in this group of patients. DN is a modified blood CP compared with HTK, which is purely crystalloid and this might in part contribute to the higher edema scores with HTK. This finding along with more myofibrillar disarray in the HTK group explains the better recovery of myocardial function in patients with DN CP. Although it is a matter of conjecture, we also believe that these changes might be due to less reperfusion injury in the DN group, which is revealed by a pattern of cardiac enzyme release in this study.

Last but not the least, in a developing country like India, anything that has equal efficacy with less cost will always be preferred. DN CP is prepared by our perfusionists in the operating room at a cost much less than for the prepacked HTK solution.

\section{Study Limitation}

The age of the patients in our cohort were older than for the data available from most centers worldwide. These patients are thus exposed to the harmful effects of longstanding cyanosis, which might affect postoperative recovery. Longstanding right ventricular outflow tract obstruction leading to extensive hypertrophy can also influence the results of myocardial biopsy. TOF formed a large percentage of cyanotic patients undergoing biventricular repair in our setup and hence were chosen in the study, thus leading to lack of variability in study population. Larger sample size would have been a better representation of the study population. We could not measure coronary sinus blood levels for determination of inflammatory markers because of a lack of facilities. Invasive CI monitoring is a more accurate indicator of predicting myocardial function; however, lack of equipment for measuring those led us to use ICON (ICON Osypka Medical $\mathrm{GmBH}$ ) monitoring, which, though reasonably accurate, lacks the precision of invasive monitoring. Therefore, as has been discussed in the section on monitoring CI, its use as the modality of determining CI compared with invasive methods is to be interpreted with caution.

\section{CONCLUSIONS}

Compared with HTK CP, the DN CP was associated with better preservation of $\mathrm{CI}$, less duration of mechanical ventilation, ICU, and hospital stays, lower ISs, lower occurrence of low cardiac output state, and less release of Trop-I. Electron microscopy showed less myocardia edema and better preservation of the myofibrillar architecture and glycogen stores in the DN group. These findings need to be validated further in larger studies on patients with more complex diagnoses and in multiple setups. 


\section{Webcast}

You can watch a Webcast of this AATS meeting presentation by going to: https://aats.blob.core.windows.net/ media/18Apr29/30ABC\%20Congenital\%20SS/S52_1_ webcast_031740422.mp4.

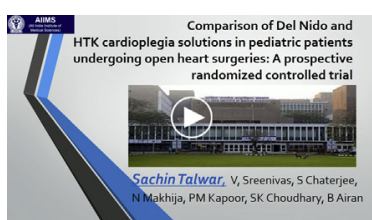

\section{Conflict of Interest Statement}

Authors have nothing to disclose with regard to commercial support.

\section{References}

1. Talwar S. Controversies in managing cardiopulmonary bypass in neonates and adults. IJECT. 2010;20:12-7.

2. Talwar S, Keshri VK. Myocardial protection in neonates and infants: what have we learnt? Where do we go? J Heart Circ. 2015;1:1-7.

3. Talwar S, Bhoje A. Comparison of del Nido and St Thomas cardioplegia solutions in pediatric patients: a prospective randomized controlled trial. Semin Thorac Cardiovasc Surg. 2017;29:366-74.

4. Bretschneider HJ, Hübner G, Knoll D, Lohr B, Nordbeck H, Spieckermann PG. Myocardial resistance and tolerance to ischemia: physiological and biochemical basis. J Cardiovasc Surg (Torino). 1975;16:241-60.

5. Narula J, Chauhan S. Electrical cardiometry: a reliable solution to cardiac output estimation in children with structural heart disease. J Cardiothorac Vasc Anesth. 2017;31:912-7.

6. Barade P, Jindal GD, Singhal R, Deepak KK. New method of electrode placement for determination of cardiac output using impedance cardiography. Indian $J$ Physiol Pharmacol. 2006;50:234-40.

7. Malik V, Subramanian A, Chauhan S. Correlation of electric cardiometry and continuous thermodilution cardiac output monitoring systems. World J Cardiovasc Surg. 2014:4:101-8.

8. Talwar S, Selvam MS. Effect of administration of allopurinol on postoperative outcomes in patients undergoing intracardiac repair of tetralogy of Fallot. Semin Thorac Cardiovasc Surg. 2018;155:335-43.

9. Gaies MG, Gurney JG, Yen AH, Napoli ML, Gajarski RJ, Ohye RG, et al. Vasoactive-inotropic score as a predictor of morbidity and mortality in infants after cardiopulmonary bypass. Pediatr Crit Care Med. 2010;11:234-8.

10. Ozisika K, Yildirima E, Solarogluc I. Ultrastructural changes of rat cardiac myocytes in a time-dependent manner after traumatic brain injury. Am J Transplant. 2004:4:900-4.

11. Edelman JJ, Seco M, Dunne B, Matzelle SJ, Murphy M, Joshi P, et al. Custodiol for myocardial protection and preservation: a systematic review. Ann Cardiothorac Surg. 2013;2:717-28.

12. Modi P, Suleiman MS, Reeves B, Pawade A, Parry AJ, Angelini GD, et al. Myocardial metabolic changes during pediatric cardiac surgery: a randomized study of 3 cardioplegic techniques. J Thorac Cardiovasc Surg. 2004;128:67-75.

13. Sinha P, Zurakowski D, Jonas R. Comparison of two cardioplegia solutions using thermodilution cardiac output in neonates and infants. Ann Thorac Surg. 2008; 86:1613-9.

14. Meissner G, Henderson JS. Rapid calcium release from cardiac sarcoplasmic reticulum vesicles is dependent on calcium and is modulated by magnesium, adenine nucleotide and calmodulin. J Biol Chem. 1987;262:3065-73.

15. Ventucci LA, Trafford AW, Oneil SC. The sarcoplasmic reticulum and arrhythmogenic calcium release. Cardiovasc Res. 2008;77:285-92.

16. Chambers DJ. Mechanisms and alternative methods of achieving cardiac arrest. Ann Thorac Surg. 2003;75:S661-6.

17. Hearse BJ, O'Brien K, Braimbridge MV. Protection of the myocardium during ischemic arrest. Dose-response curves for procaine and lignocaine in cardioplegic solutions. J Thorac Cardiovasc Surg. 1981;81:873-9.
18. Sarraf N, Thalib L, Hughes A, Houlihan M. Cross clamp time is an independent predictor of mortality and morbidity in low and high-risk cardiac patients. Int $J$ Surg. 2001;9:104-9.

19. Imura H, Modi P, Pawade A, Parry AJ, Suleiman MS, Angelini GD, et al. Cardiac troponin I in neonates undergoing the arterial switch operation. Ann Thorac Surg. 2002; 74:1998-2002.

20. Croal BL, Hillis GS, Gibson PH, Fazal MT, El-Shafei H, Gibson G, et al. Relationship between postoperative cardiac troponin I levels and outcome of cardiac surgery. Circulation. 2006;114:1468-75.

21. Bojan M, Peperstraete H, Lilot M, Tourneur L, Vouhe P, Pouard P. Cold histidinetryptophan-ketoglutarate solution and repeated oxygenated warm blood cardioplegia in neonates with arterial switch operation. Ann Thorac Surg. 2013;95: 1390-6.

22. Meldrum DR, Meng X, Dinarello CA, Ayala A, Cain BS. Human myocardial tissue TNF expression following acute global ischemia in-vivo. J Mol Cell Cardiol. 1998;30:1683-9.

Key Words: myocardial protection, cardioplegia, congenital heart disease, tetralogy of Fallot

\section{Discussion}

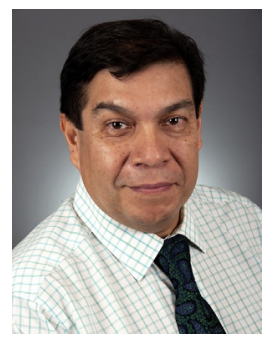

Pedro J. del Nido (Boston, Mass). Thank you, Dr Talwar. First of all, thank you for sending me the manuscript well ahead of time. It was very helpful and it was very interesting to read your results. I also have to commend you for doing a prospective randomized study actually comparing two methods of myocardial protection, and your group has really led the way in applying this methodology to answer some of our questions.

I have a few questions for you regarding the study. I noted that there are significant differences, and I think you pointed this out, in the volume of cardioplegia that's given in the HTK versus the DN group, and I realize that this is in great part due to the prescribed method for applying the HTK. Can you comment on what potential impact that extra volume could have on some of the measurements that you made, particularly in the early postoperative period?

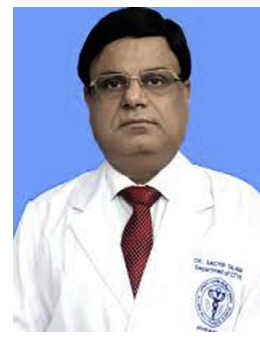

Dr Sachin Talwar (New Delhi, India). As far as the extra volume of the HTK solution, in both groups we open the right atrium and suck out the extra volume of the effluent, but I believe that the larger volume of the HTK solution might be responsible for the higher incidence of myocardial edema that we noticed on electron microscopy. I think that's one of the reasons. Otherwise if you see the ultrafiltration volume, that gets filtered out during the period of ultrafiltration.

Dr del Nido. So along those lines, you used standard ultrafiltration during the procedure for both, and the volume that you removed is about equivalent for both. 
Dr Talwar. Yes.

Dr del Nido. If the cardioplegia volume was far greater, do you think that more aggressive ultrafiltration in the HTK group may have given you a different result?

Dr Talwar. That's difficult to say, because when we start the administration of cardioplegia, the first thing we do is open the right atrium in both of the groups and suck out the cardioplegia. So you are actually not adding any volume to the pump. But, yes, if we were not to do the ultrafiltration, then we probably would end up having a lot of hyponatremia, because the HTK solution is very low in sodium, there will be more hemodilution, you would need to add more blood, and all those factors would come into play at that time.

Dr del Nido. Thank you. The other observation I made is that your troponin levels were clearly elevated. They were initially elevated in all groups, which is no surprise, you did a ventriculotomy, but they were elevated still at 24 hours, and particularly in the HTK group. Do you have any further data? In other words, how long does this troponin-I release last in these children?

Dr Talwar. In our study, the last point that we measured the troponin-I was at 24 hours. So beyond that we did not do measurements. But I guess that would be a good thing to do in future studies.

Dr del Nido. I think it would be interesting, because it implies that there is ongoing injury and that's what you would want to get at are the things that we can do in the post reperfusion period to improve it.

Dr Talwar. Yes.

Dr del Nido. And the final question I have relates to the fact that you have all your indices of postoperative function being markedly elevated for a prolonged period of time, yet in the biopsies that you had at the end of 45 minutes of ischemia, this is before reperfusion occurred, the mitochondria, which are really the engine of that myocardium, were still intact and they were still preserved in both groups. How do you explain that difference? Is there a mechanism that might explain why you were able to see intact mitochondria during the ischemia period but yet have all the dysfunction in the postoperative period?
Dr Talwar. If you see our previous study that we presented the year before last in which we compared the del Nido cardioplegia with the St. Thomas, we followed the same protocol, and our biopsies were obtained at 45 minutes after the clamp. Looking back, I see that, because both the solutions are very long acting, it would probably do well in a future study to take the biopsies at a later time, that is one thing, and that would typically be around 80 or 90 minutes. So probably we might be able to get the electron microscopic features in a better fashion if we postponed the time of biopsy.

The second thing I see for all of the ischemia and reperfusion in the myocardial damage, in the next study which we have designed we are looking at the levels of the superoxide dismutase. That will tell us whether the ischemia and reperfusion is also playing a role in myocardial protection. So far it appears that the beneficial effects of the del Nido cardioplegia will be HTK. The ischemia/ reperfusion seems to play a large role, but we need to prove that in a future study.

Dr del Nido. Right. Thank you very much. The other comment I would make is that both of these formulations have a large amount of buffering capacity, and that was in fact the rationale behind a lot of this effort. In fact, in my view, and this may be borne out by your study, is that the buffering capacity adds something, but it's clearly not the major factor.

Thank you very much. I enjoyed reading your manuscript.

Dr Talwar. Thank you.

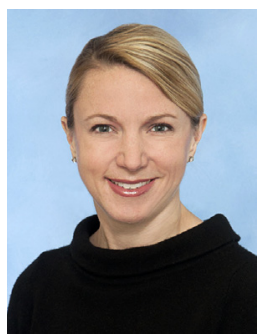

Dr Jennifer Romano (Ann Arbor, Mich). What is your current cardioplegia strategy then for patients? Is it selective for underlying diagnoses and age?

Dr Talwar. No. Formally across the board we are using the del Nido cardioplegia currently. This study was basically a plan to see how they match up with each other. Our current strategy is a single shot of del Nido cardioplegia. 


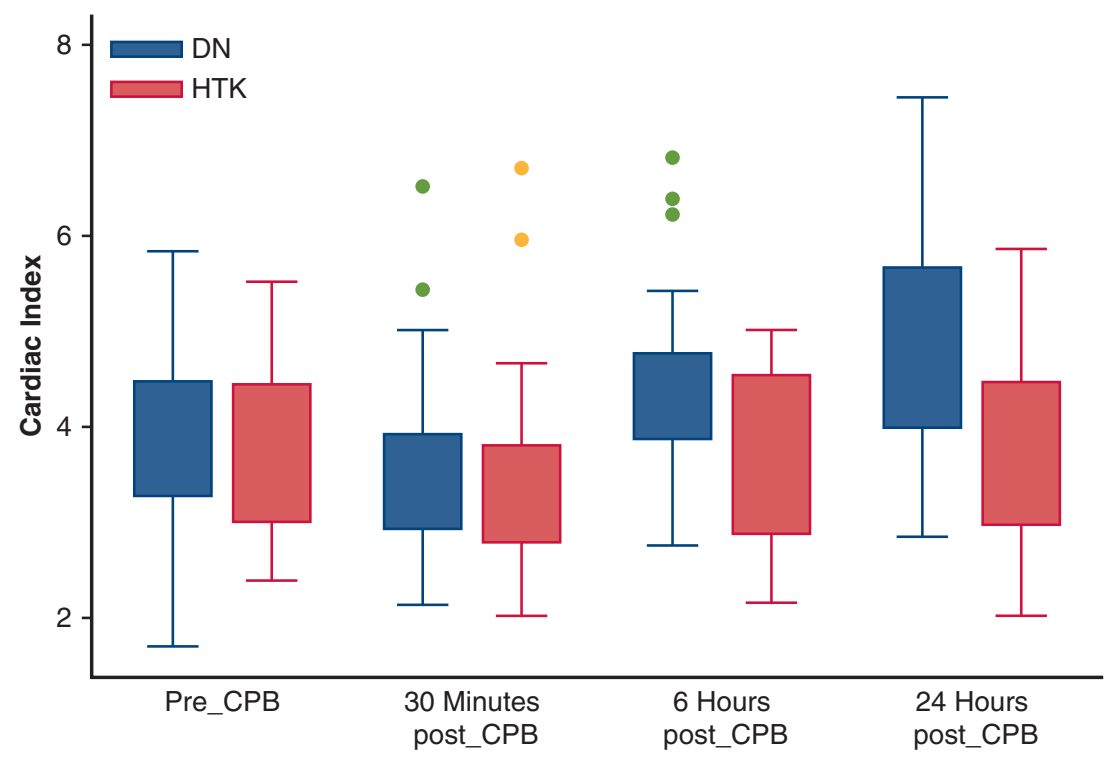

FIGURE E1. Box plot showing the cardiac index $\left(\mathrm{L} / \mathrm{min} / \mathrm{m}^{2}\right)$ in the 2 groups. Although the cardiac index decreased after termination of cardiopulmonary bypass (post_CPB) compared with the values before cardiopulmonary bypass $($ Pre_CPB) in both the groups, they were lower in the histidine-tryptophanketoglutarate $(H T K)$ group compared with the del Nido $(D N)$ group at the first reading post_CPB, but were not statistically significant. However, the values were significantly higher in DN group at 6 and 24 hours post_CPB $(P=.005$ and $P<.001$, respectively).

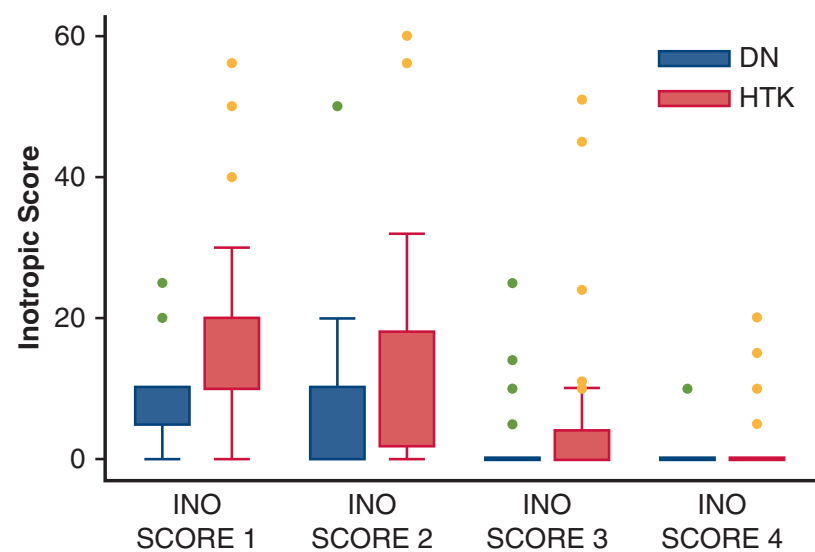

FIGURE E2. Box plot showing ionotropic score (INO SCORE) of the del Nido $(D N)$ group and histidine-tryptophan-ketoglutarate $(H T K)$ group for the first 4 days. The INO SCORE pattern shows better recovery of myocardial function in the DN group. The mean INO SCORE at the end of first 24 hours (INO SCORE 1), in the second 24 hours (INO SCORE 2), and in the third (INO SCORE 3) and fourth 24 hours (INO SCORE 4) was significantly lower in the DN group $(P=.021, P=.036, P=.026$, and $P=.008$, respectively). 